\section{Neutrality and} acidity

\section{Peter Brimblecombe}

Acid Rain: Rhetoric and Reality. By Chris C. Park. Methuen: 1987. Pp.272. £30, $\$ 39.95$. (Methuen Academic has now been incorporated into Routledge.)

RHETORIC and reality are imaginative concepts to apply to the 'acid rain debate'. The words roll off the tongue with such ease that one might wonder if the title of this book isn't itself mere rhetoric. The reader does not have to go far into the text, however, to discover that Chris Park has been careful to give us a broad and informative account of the subject.

Anyone who writes about acid rain risks being accused of bias; the arguments are such that even the most neutral author wil be forced to take stands which will ally him with one school of thought or another. It is an indication of Park's struggle for a position of thoughtful neutrality that most informed readers will be able to find points of disagreement with him.

His first difficulty was that of defining acid rain. The choice of definition is frequently driven by a need to explain the effects attributed to acid rain more than by a desire to define some physically observable entity. As a result, the chemical description of acid rain as a pollutant has broadened over the years. Park avoids the widest of definitions by seeing acid rain as derived largely from anthropogenic $\mathrm{SO}_{2}$ and $\mathrm{NO}_{x}$ emissions. This may explain his cursory treatment of ozone damage to forests and his subtle shifts between questions of urban and of rural pollution. True, reading carefully, it is clear when the author is writing of acid rain and when he is considering urban air pollution, but for many the two may seem synonymous.

The book is intended for the general reader, and source materials have been gleaned from The Times almost as often as from the scientific literature; the result is a sense of immediacy. References to scientists tend to be personal, creating an image of them as real people grappling with a complex problem. By contrast, Greenpeace, Friends of the Earth and, more especially, the Central Electricity Generating Board, emerge as monoliths.

The book centres on Western Europe and North America, so we only catch glimpses of the enormous technical and administrative problems caused by the acid-rain problem in Eastern Europe. The author treats the slow emergence of scientific understanding, public interest and legislation very well. The complexities of air and soil chemistry are mentioned rather than discussed in detail, but Park takes pains to show that the public airing of those complexities by scientists is often more than mere rhetoric designed to impede progress in resolving the problem. The chapter on technological solutions was one of my favourites, no doubt because the sociological and legislative solutions are so much more complicated.

There is such a huge volume of literature on the issues surrounding acid rain that an author has difficulty in deciding where to stop. For the general reader, Park may have erred on the generous side. Conversely, although much of the

\section{Fooling predators}

\section{J.L. Cloudsley-Thompson}

The Biology of the Reptilia, Vol. 16 Ecology B: Defense and Life History. Edited by Carl Gans and Raymond B. Huey. Alan R. Liss: 1988. Pp.659. \$74.50, £66.

How can a brightly coloured coral snake serve as a batesian model for less-harmful species if its bite is lethal? This paradox has led several investigators to suggest that mildly poisonous rear-fanged species with coral-snake patterns may be the models, while non-venomous and frontfanged species are respectively batesian and müllerian mimics. The name mertensian mimicry has been applied to this hypothesis.

According to F. Harvey Pough, who discusses mimicry and related phenomena in this the latest volume in the series Bio$\log y$ of the Reptilia, uncertainties about the probability of envenomation of a predator by a snake, and the toxicity of different venoms, preclude complete evaluation of the hypothesis. Colubric snakes may be weak müllerian mimics of venomous coral snakes, but they are unlikely to be the species on which the mimicry complex is based. Indeed, coral snakes may well be avoided mainly because they are unpalatable - scavenging birds in Costa Rica, which quickly consume other snakes killed on the roads, apparently leave dead coral snakes undisturbed. Because of the improbability of observing events such as encounters between predators and models or their mimics in nature, the evaluation of alleged examples of mimicry has to be based on indirect evidence.

The arguments outlined above are typical of many to be found in this volume, which is dedicated primarily to topics of ecology and behaviour. The first chapter, by Harry W. Greene, consists of a review of anti-predator mechanisms. Although reptiles frequently prey on invertebrates, the reverse is exceptional. Nevertheless, large centipedes, spiders and scorpions do sometimes eat reptiles and other verte- material will be well known to specialists, there is plenty to rekindle their imaginations. For example Park reminded me relatively early in the book that atmospheric acidity could arise from a decline in the alkalinity of the atmosphere, a result of removing alkaline fly ash particles from large coal-burning sources. Altogether this book is a praiseworthy effort making 'reality' accessible to a wide audience.

Peter Brimblecombe is a Lecturer in the School of Environmental Sciences, University of East Anglia, Norwich NR4 7TJ, UK.

brates; turtles are occasionally the prey of octopuses, while crabs constitute formidable predators of their hatchlings. Not much is known of the defence mechanisms of turtles or crocodiles, and morphological defences in general have been little studied - apart from epidermal sound production and hissing in some snakes, the protective shells of tortoises and turtles, and the erection of frills by the bearded dragon Amphibolurus barbatus. Such structural features challenge the evolutionary biologist because they often reflect the functional demands of multiple biological roles.

The examples cited above show that the study of reptiles has wider implications than the non-herpetologist might realize. Nor is there any lack of 'corroborative detail' in the book, even if the narrative were to be thought of as 'bald and unconvincing'. For instance, E. N. Arnold devotes an entire chapter to caudal autotomy, while Richard Snine contributes another on parental care. The proportion of species showing this is lower among reptiles than among amphibians or freshwater teleost fishes, a difference which may reflect the absence of male parental care in squamates.

The second half of this large book consists of four multi-author chapters which outline methods for the study of reptile populations, evolution in turtles, lifehistory patterns in squamate reptiles, and the physiological ecology of reptilian eggs and embryos. Not only do they indicate the enormous amount of field work that has been undertaken in recent years but, even more interesting, they draw attention to the numerous gaps that still exist in our knowledge of reptile biology.

J.L. Cloudsley-Thompson, Department of Biology (Medawar Building), University College London, Gower Street, London WC1E 6BT, UK, is Emeritus Professor of Zoology in the University of London.

- Recently published by Cambridge University Press in their Studies in Ecology series is Community Ecology and Salamander Guilds by Nelson G. Hairston, Sr. The salamander is a good subject of research because it exists in stable populations, and is used here as an example to illustrate the theories of community ecology. Price is $£ 27.50, \$ 44.50$. 